\title{
Aplikasi Pengenalan Rambu Lalu Lintas Menggunakan Metode Fuzzy Mamdani Berbasis Android
}

\author{
Junianto Ismail $^{1}$, Fitri Marisa ${ }^{2}$, Indra Dharma Wijaya ${ }^{3}$
}

\begin{abstract}
Drive is the one human activity that is often done to travel from one place to another, the cases of accidents that occur from year to year. It is regarded as the author of the cause of the low level of public awareness about the importance of obeying traffic signs in order to increase the safety drive. Thus, designed an application introduction of traffic signs using the method of mamdani fuzzy -based android, which is expected to give understanding and learning to the community of the importance of drive

Berkendara adalah salah satu aktivitas manusia yang sering dilakukan untuk melakukan perjalanan dari satu tempat ke tempat yang lain, Kasus kecelakaan yang terjadi dari tahun ke tahun semakin meningkat. Hal tersebut dipandang penulis sebagai penyebab rendahnya tingkat kesadaran masyarakat tentang pentingnya mematuhi rambu lalu lintas guna meningkatkan keselamatan berkendara. Maka dari itu, dirancang sebuah aplikasi pengenalan rambu lalu lintas menggunakan metode fuzzy mamdani berbasis android, yang diharapkan dapat memberi pemahaman dan pembelajaran kepada masyarakat akan pentingnya berkendara

Kata kunci: rambu lalu lintas, aplikasi pengenalan rambu, Fuzzy
\end{abstract} mamdani.

\section{A. Latar Belakang}

\section{I.Pendahuluan}

Lalu lintas merupakan hal yang penting untuk meningkat pergerakan masyarakat sehingga negara merasa penting untuk mengaturnya sesuai dengan perkembangan zaman, agar terjaganya hak-hak masyarakat dalam menggunakan jalanan. Jika kita membahas tentang negara maka setiap individu yang ada di dalam negara tersebut secara otomatis memberikan wewenang kepada negara untuk mengatur hak-hak ataupun membuat aturan-aturan terhadap individu itu sendiri dengan timbal balik negara memberikan hak-hak kita kembali kepada setiap individu masing-masing, itulah suatu kewajiban individu tersebut sebagai pemegang status warga negara(Muhammad Awaluddin, 2016).

Kecelakaan lalu lintas merupakan suatu kejadian yang sering sekali terjadi disekitar kita. Meskipun telah banyak sistem keamanan pada kendaraan yang sengaja dirancang oleh pihak industri kendaraan untuk mengurangi tingkat terjadinya kecelakaan, namun kecelakaan tetap saja tidak dapat dihindari. Banyak faktor yang menyebabkan terjadinya kecelakaan lalu lintas, diantaranya adalah faktor cuaca, kendaraan, kondisi jalan maupun kebiasaan pengendara kendaraan (Akin \& Akbas, 2010).

Keamanan berkendara mengandung pengertian yaitu suatu usaha yang dilakukan dalam meminimalisir tingkat bahaya dan memaksimalkan keamanan dalam berkendara, demi menciptakan suatu kondisi, yang mana kita berada pada titik tidak membahayakan pengendara lain dan menyadari kemungkinan bahaya yang dapat terjadi di sekitar kita serta pemahaman akan pencegahan dan penanggulangannya (Nadhillah, 2013).

Aplikasi pengenalan rambu lalu lintas berbasis android didesain untuk mensimulasikan permasalahan yang ada sehingga diperoleh esensi atau ilmu yang dapat digunakan untuk menyelesaikan permasalahan. Pemain dituntut untuk belajar sehingga dapat menyelesaikan permasalahan yang ada. Menurut penelitian yang dilakukan oleh Torrente dkk (2009) tentang perancangan educational pengenalan rambu lalu lintas, penelitian tersebut belum menerapkan kecerdasan buatan, sehingga tidak mencerminkan karakter pendidik yang sebenarnya dan menimbulkan kebosanan bagi pemain itu sendiri. Dalam hal ini, kecerdasan buatan mempunyai peran penting yang mampu membentuk karakter-karakter dalam pengenalan rambu lalu lintas yang didasarkan pada simulasi pemikiran dan perilaku manusia dalam mesin (Kose, 2012). Salah satu metode dalam kecerdasan buatan yang dapat diaplikasikan dalam pengenalan rambu lalu lintas adalah logika Fuzzy(Pirovano, 2012).

Logika Fuzzy merupakan teknik yang bisa membantu menaikkan kualitas interaksi pemain pengenalan rambu lalu lintas (Mashudi, 2012). Logika Fuzzy Mamdani bertindak sebagai pengontrol perilaku penegak disiplin, dalam pengenalan rambu lalu lintas ini adalah polisi. Peran polisi, apabila pemain melanggar rambu-rambu lalu lintas akan ditindak tegas seperti pemain dikejar apabila melanggar dengan parameter pelanggaran, waktu dan level.

\section{B. Rumusan Masalah}

Berikut rumusan masalah pada penelitian ini :

1) Bagaimana menerapkan metode fuzzy mamdani ke dalam aplikasi pengenalan rambu lalu lintas berbasis Android

2) Bagaimana memberikan pemahaman tentang pentingnya berkendara dalam mematuhi tata tertib peraturan berlalu lintas ke dalam aplikasi pengenalan rambu lalu lintas menggunakan metode fuzzy mamdani berbasis android

\section{A. Logika Fuzzy}

\section{II.Landasan Teori}

Logika fuzzy adalah cabang dari sistem kecerdasan buatan (Artificial Intelegent) yang meniru kemampuan manusia dalam berfikir ke dalam bentuk algoritma yang kemudian dijalankan oleh mesin. Algoritma ini digunakan dalam

${ }^{1}$ Mahasiswa, Universitas Widyagama, jln.Borobudur 35 Malang 65128 INDONESIA(telp: 085655515514 e-mail: 
berbagai aplikasi pemrosesan data yang tidak dapat direpresentasikan dalam bentuk biner. Logika fuzzy menginterpretasikan statemen yang samar menjadi sebuah pengertian yang logis.

\section{B. $U M L$}

Unified Modeling Language (UML) adalah keluarga notasi grafis yang didukung oleh meta-model tunggal, yang membantu pendeskripsian dan desain sistem perangkat lunak, khususnya sistem yang dibangun menggunakan pemrograman berorientasi objek (OOP).

Bahasa UML digunakan untuk menentukan, memvisualisasikan, membangun, dan mendokumentasikan suatu sistem informasi. UML dikembangkan sebagai suatu alat untuk analisis dan desain berorientasi objek, namun demikian UML dapat digunakan untuk memahami dan mendokumentasikan setiap sistem informasi. Hal tersebut membuat penggunaan UML dalam industri terus meningkat. Ini merupakan standar terbuka yang menjadikannya sebagai bahasa pemodelan yang umum dalam industri piranti lunak dan pengembangan sistem.

\section{Android}

Android adalah sistem operasi berbasis Linux yang dirancang untuk perangkat seluler layar sentuh seperti telepon pintar dan komputer tablet. Android awalnya dikembangkan oleh Android, Inc., dengan dukungan finansial dari Google, yang kemudian membelinya pada tahun 2005 . Sistem operasi ini dirilis secara resmi pada tahun 2007, bersamaan dengan didirikannya Open Handset Alliance, konsorsium dari perusahaan-perusahaan perangkat keras, perangkat lunak, dan telekomunikasi yang bertujuan untuk memajukan standar terbuka perangkat seluler. Ponsel Android pertama mulai dijual pada bulan Oktober 2008.

Android adalah sistem operasi dengan sumber terbuka (open source), dan Google merilis kodenya di bawah lisensi Apache. Kode dengan sumber terbuka dan lisensi perizinan pada Android memungkinkan perangkat lunak untuk dimodifikasi secara bebas dan didistribusikan oleh para pembuat perangkat, operator nirkabel, dan pengembang aplikasi. Selain itu, Android memiliki sejumlah besar komunitas pengembang aplikasi (apps) yang memperluas fungsionalitas perangkat, umumnya ditulis dalam versi kustomisasi bahasa pemrograman Java.

\section{Adobe Flash}

Flash merupakan software yang memiliki kemampuan menggambar sekaligus menganimasikan serta mudah dipelajari. Di samping digunakan untuk keperluan pembuatan animasi biasa dan animasi sirus web, Flash juga dapat digunakan untuk membuat game, presentasi, dan animasi kartun. Sekarang juga sudah mulai berkembang penggunaan Flash untuk pembuatan game di mobile device seperti handpone,PDA, dll.

Animasi yang dihasilkan Flash adalah animasi berupa file movie. Movie yang dihasilkan dapat berupa grafik atau teks. Grafik yang dimaksud disini adalah grafik yang berbasis vektor. Jadi ketika diakses melalui internet, animasi yang akan ditampilkan lebih cepat dan terlihat halus. Selain itu, Flash juga memiliki kemampuan untuk mengimpor file suara, video maupun file gambar dari aplikasi lain.grafik yang berbasis vektor. Jadi ketika diakses melalui internet, animasi yang akan ditampilkan lebih cepat dan terlihat halus. Selain itu, Flash juga memiliki kemampuan untuk mengimpor file suara, video maupun file gambar dari aplikasi lain.

\section{E. Rambu Lalu-Lintas}

Rambu lalu lintas adalah salah satu alat perlengkapan jalan dalam bentuk tertentu yang memuat lambang, huruf, angka, kalimat, atau perpaduan diantaranya yang digunakan, untuk memeberi peringatan, petunjuk, larangan dan perintah bagi pengguna jalan. Lalu lintas adalah gerak kendaraan dan orang di ruang lalu lintas jalan. Sebenarnya hal yang pertama dan harus diketahui oleh masyarakat adalah mengenal dan mengetahui arti dan maksud dari rambu-rambu lalu-lintas yang di sediakan atau terpasang di jalan umum.(UndangUndang RI.2004)

\section{A. Analisis system}

\section{Analisis dan Perancangan Sistem}

Pengenalan rambu-rambu lalu lintas saat ini dilakukan dengan cara otodidak, dari guru di sekolah atau belajar dari buku. Kendala pembelajaran seperti ini menyebabkan sulit dimengerti dan membosankan karena tidak menarik dan hanya teori sehingga masyarakat malas belajar.

Kendala seperti yang disebutkan diatas menyebabkan mayoritas masyarakat tidak mengetahui arti rambu-rambu lalu lintas yang terpasang di jalan raya. Sehingga tidak heran bahwa banyak terjadinya kecelakaan lalu lintas dan juga kena tilang.

\section{B. Perancangan Logika Fuzzy}

1) Fungsi Pelanggaran $(\mathrm{P})$

Nilai maksimal yang dimiliki himpunan patuh adalah 10 dan himpunan langgar 100. Fungsi keanggotaan Pelanggaran dengan himpunan fuzzy patuh dan langgar seperti dibawah ini

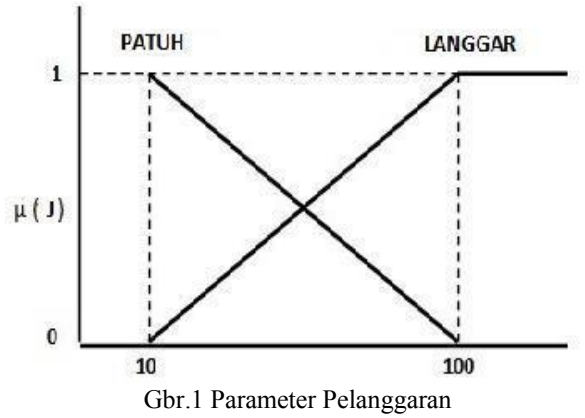

2) Fungsi Keanggotaan Level (1)

Nilai maksimal yang dimiliki himpunan level 1 adalah 1 dan himpunan level 2, maka terbentuklah fungsi keanggotaan level dengan himpunan fuzzy level 1 dan level 2 seperti dibawah ini 


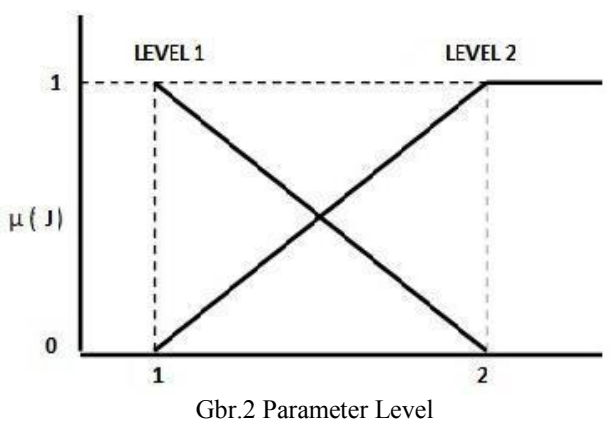

3) Fungsi Keanggotaan Waktu (W)

Nilai maksimal yang dimiliki himpunan waktu adalah 10 detik dan himpunan waktu 60 detik, maka terbentuklah fungsi keanggotaan waktu dengan himpunan fuzzy sebentar dan lama seperti dibawah ini (Kusumadewi dan Purnomo, 2010)

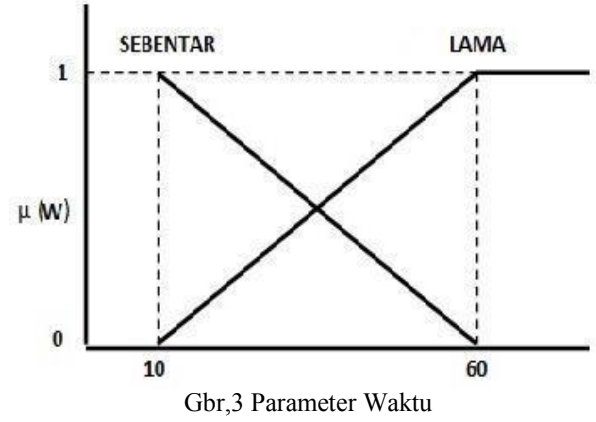

4) Perancangan Rule Base System

Setelah proses pembuatan fungsi keanggotaan, dilakukan pembuatan rule base system. Sebelum membuat rule base system tentukan dulu nilai diagram fuzzy output (Z).

\begin{tabular}{|c|c|c|c|c|}
\hline IF & $\begin{array}{c}\text { PELANGGARAN } \\
\text { (P) }\end{array}$ & $\begin{array}{l}\text { LEVEL } \\
\text { (L) }\end{array}$ & $\begin{array}{l}\text { WAKTU } \\
\text { (W) }\end{array}$ & $\begin{array}{l}\text { FUZZY } \\
\text { OUTPUT } \\
\text { (F) }\end{array}$ \\
\hline R1 & PATUH & LEVEL 1 & SEBENTAR & PATROLI \\
\hline $\mathrm{R} 2$ & PATUH & LEVEL 1 & LAMA & PATROLI \\
\hline $\mathrm{R} 3$ & PATUH & LEVEL 2 & SEBENTAR & PATROLI \\
\hline $\mathrm{R} 4$ & PATUH & LEVEL 2 & LAMA & PATROLI \\
\hline R5 & LANGGAR & LEVEL 1 & SEBENTAR & TILANG \\
\hline $\mathrm{R} 6$ & LANGGAR & LEVEL 1 & LAMA & TILANG \\
\hline $\mathrm{R} 7$ & LANGGAR & LEVEL 2 & SEBENTAR & TILANG \\
\hline $\mathrm{R} 8$ & LANGGAR & LEVEL 2 & LAMA & TILANG \\
\hline
\end{tabular}

\section{5) Perhitugan Fuzzy}

- Pelanggaran (LANGGAR)

Pelanggaran berada pada area langgar, maka dapat dihitung menggunakan Persamaan 3.2
Langgar : $100-10 / 90$$$
=1
$$
Patuh : :0

- Level (1)

Level 1 berada pada area level 1, maka dapat dihitung menggunakan Persamaan 3.3

Level $1: 1$

Level 2 : 0

- Waktu (60)

Waktu 60 berada pada area lama, maka dapat dihitung menggunakan Persamaan 3.5
Lama : $60-50 / 10$
$=1$

Level 2 :0

Setelah derajat keanggotaan diketahui, masuk kedalam tahapan rule base system. Rule base system diproses dan dicari yang cocok sesuai dengan derajat keanggotaan. Rule base system secara lengkap disajikan dalam Tabel 1 Hasil rule base yang cocok adalah rule 6 . Selanjutnya, nilai tiap variabel diambil minimumnya dari setiap rule base

R6. IF pelanggaran LANGGAR OR level LEVEL 1 OR waktu LAMA THEN TILANG

Apredikat $\quad=$ MAX $(1 ; 1 ; 1)$

$$
\mathrm{Z1}=\mathrm{TILANG}=100
$$

Proses pengambilan keputusan fuzzy Mamdani menggunakan perhitungan weight average :$$
=(\text { apredikat } 1 \times \mathrm{Z} 1)
$$$$
\text { apredikat1 }
$$

$$
\begin{aligned}
& =(1 \times 100) \\
& =100(\text { TILANG })
\end{aligned}
$$

\section{Use Case Diagram}

Struktur menu pada aplikasi pengenalan rambu lalu lintas dirancang khusus pada platform android menggunakan adobe flash. Diagram use case mendeskripsikan sebuah interaksi antara satu atau lebih aktor dengan sistem yang akan dibuat. Berikut Use Case diagram aplikasi disajikan pada Gambar 4

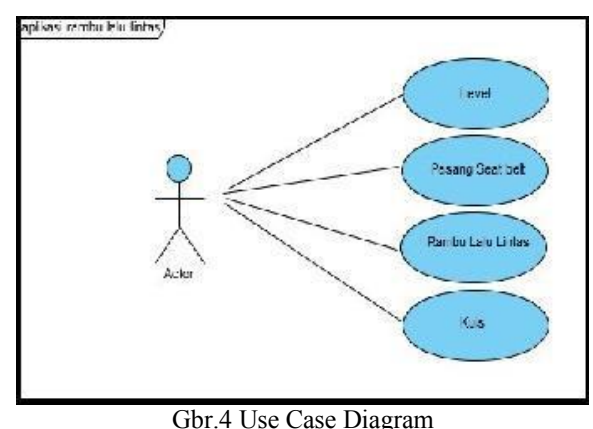

Pada Gambar 4 dijelaskan bahwa terdapat beberapa rambu lalu lintas yang dipasang setiap perlintasan jalan. Rambu yang dipasang bertujuan agar dipatuhi semua rambu yang ada. Selain rambu yang harus diperhatikan adalah kelengkapan pengendara yaitu seat belt, apabila terjadi pelanggaran dalam 
arti melanggar rambu maka sistem mendeteksi adanya pelanggaran berdasarkan pasal lalu lintas yang berlaku, selanjutnya deteksi pelanggaran dikirim ke metode fuzzy dan diproses untuk ditindak oleh penegak disiplin (POLISI).

\section{Activity Diagram}

Activity diagram adalah tipe khusus dari diagram state yang memperlihatkan aliran dari suatu aktifitas ke aktifitas lainnya dalam suatu sistem. Diagram ini terutama penting dalam pemodelan fungsi-fungsi dalam suatu sistem dan memberi tekanan pada aliran kendali antar objek. Sebuah aktifitas dapat direalisasikan oleh satu use case atau lebih. Aktifitas menggambarkan proses yang berjalan, sementara use case menggambarkan bagaimana aktor menggunakan sistem untuk melakukan aktivitas. Berikut activity diagram

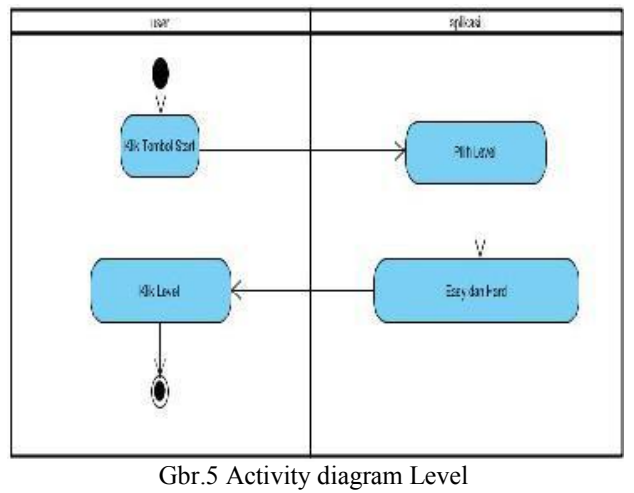

Pada gambar 5 menjelaskan bahwa ketika user menekan tombol start maka program akan menyediakan pilihan menu untuk memilih tingkatan level dalam aplikasi game, dalam menu tersebut dijelaskan bahwa terdapat 2 pilihan menu yaitu easy untuk tingkatan permainan yang mudah dan hard untuk tingkatan permainan yang sulit.

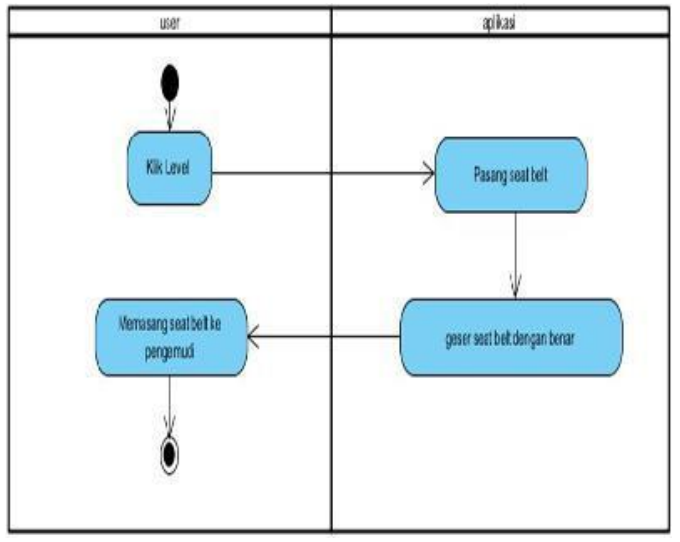

Gbr.6 Activity diagram Pasang Seat Belt

Pada gambar 6 dijelaskan bahwa ketika user selesai memilih tingkatan level maka user diperintahkan untuk memasang seat belt ke pengemudi kendaraan dengan benar

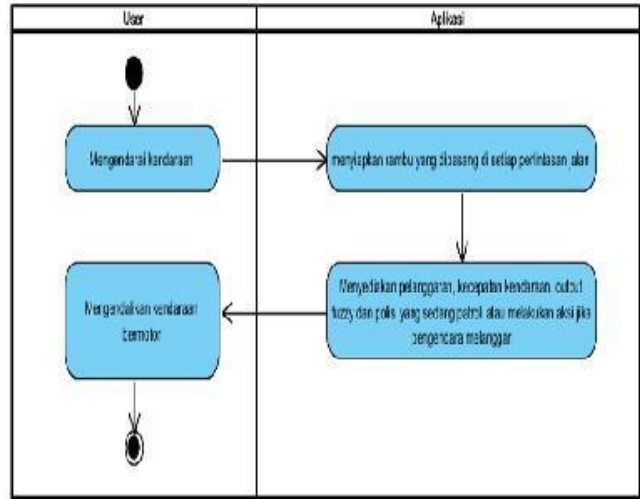

Gbr.7 Activity diagram rambu lalu lintas

Pada Gambar 7 user menjalankan kendaraan di jalan raya yang sudah disediakan rambu lalu lintas di setiap perlintasan jalan. Apabila pengendara mengikuti rambu sesuai dengan aturan yang ada, maka user dapat melanjutkan permainan ke tahap kuis hingga selesai, namun sebaliknya jika melanggar maka polisi akan melakukan tindakan

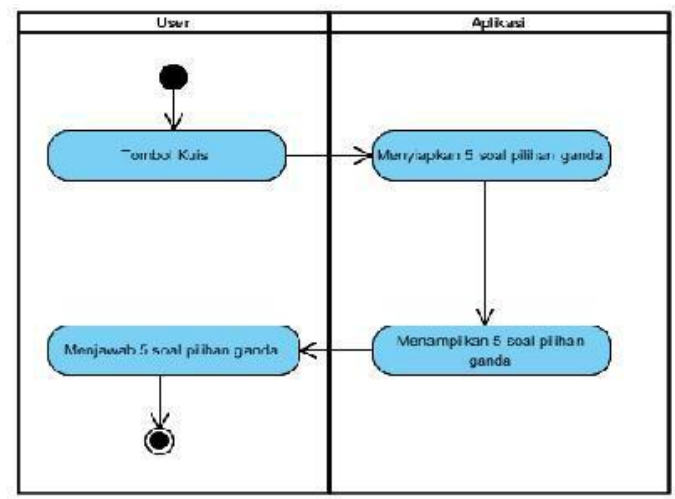

Gbr.8 Activity diagram kuis

Pada gambar 8 user menekan tombol kuis. Reaksi aplikasi menyiapkan 5 soal beserta jawaban pilihan ganda. Selanjutnya user dapat menjawab soal tersebut apabila benar maka mendapatkan 20 poin setiap jawaban, sehingga jika jawaban benar semua maka akumulasi poin 100

\section{E. Sequence Diagram}

Diagram sequence (urutan) adalah diagram interaksi yang menekankan pada pengiriman pesan (message) dalam suatu waktu tertentu. Pada Sequence diagram ini menggambarkan skenario atau rangkaian langkah-langkah yang dilakukan pada sistem sebagai respon dari sebuah event untuk menghasilkan output tertentu. Berikut sequence diagram aplikasi pengenalan rambu lalu lintas 


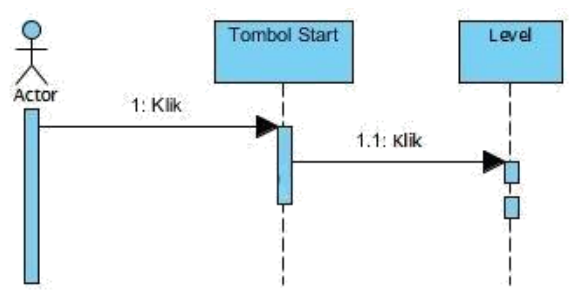

Gbr.9 Sequence Diagram Level

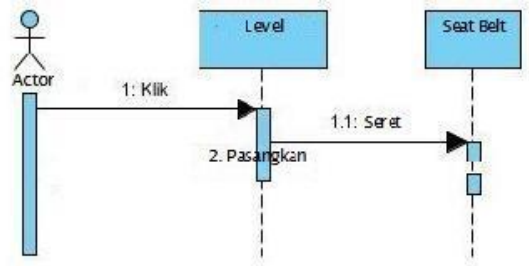

Gbr.10 Sequence Diagram Seat Belt

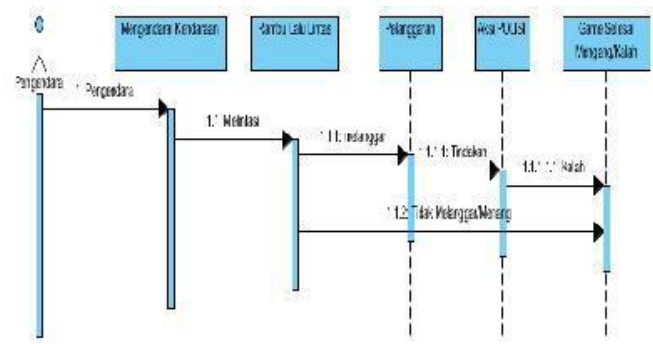

Gbr.11 Sequence Diagram Rambu Lalu Lintas

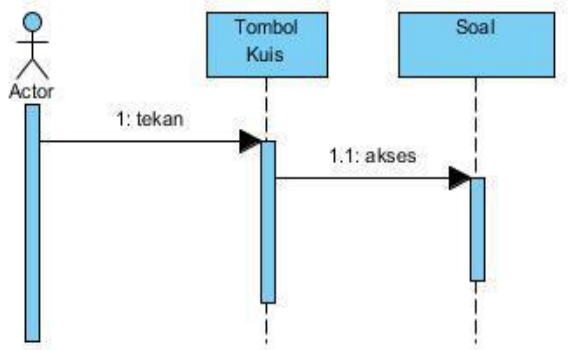

Gbr.12 Sequence Diagram Menu kuis

Pada gambar 12, user menekan tombol kuis. Reaksi aplikasi menyiapkan 5 soal beserta jawaban pilihan ganda. Selanjutnya user dapat menjawab soal tersebut apabila benar maka mendapatkan 20 poin setiap jawaban, sehingga jika jawaban benar semua maka akumulasi poin 100

\section{F. Storyboard}

Berikut ini menggambarkan storyboard atau alur proses aplikasi pengenalan rambu yang dijalankan oleh user :

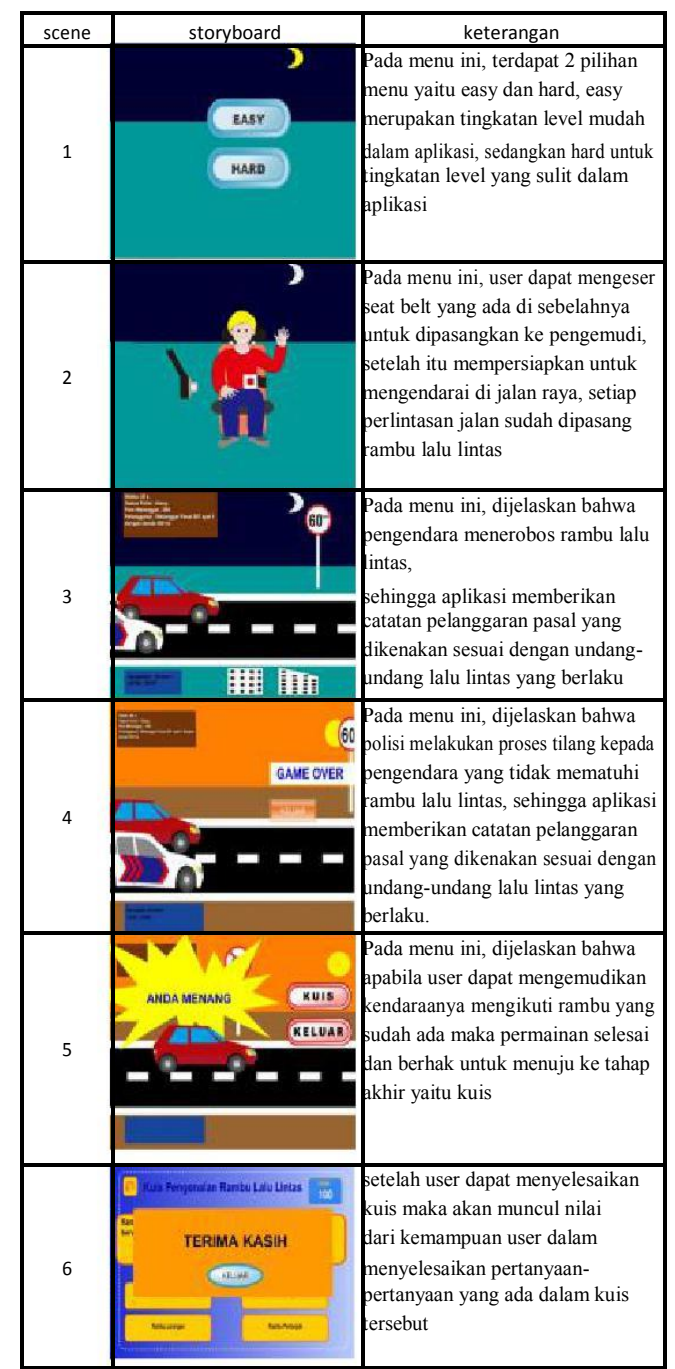

Tabel.2 Storyboard Aplikasi

\section{IV.IMPLEMENTASI DAN PENGUJIAN}

\section{A. Implementasi Sistem}

Tujuan implementasi adalah untuk menjelaskan tentang manual modul kepada semua user yang akan menggunakan aplikasi. Sehingga user tersebut dapat merespon apa yang ditampilkan dalam aplikasi dan memberikan masukan kepada pembuat aplikasi untuk dilakukan perbaikan agar sistem lebih baik lagi, dalam aplikasi ini terdapat beberapa menu diantaranya menu utama,menu level, pasang seat belt, berkendara dan kuis

Pada frame pertama dirancang untuk menu utama. Frame utama ini berisi beberapa tombol menu mulai dan keluar. Frame 1 berisi tentang mulai dan keluar, ke 2 sebagai menu utama, ke 3 merupakan pelanggaran, ke 4 rambu lalu lintas dan tombol menu, ke 5 sampai 8 adalah kuis dan pertanda game telah selesai 


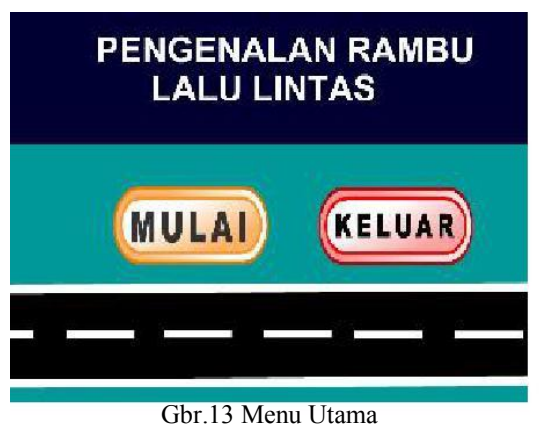

Frame kedua berisi tentang pilihan level, terdapat 2 kategori tingkatan level yaitu easy dan hard

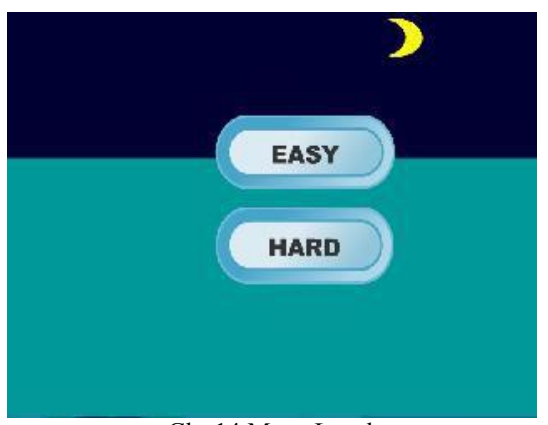

Gbr.14 Menu Level

Pada Gambar 14, ini dijelaskan user dapat memilih kategori tingkatan level yang ingin dimainkan, level terdiri dari easy dan hard dimana tiap level memiliki tigkat kesulitan yang berbeda.

Frame ketiga berisi menu pasang seat belt. Apabila berhasil memasang semua maka peserta dipersiapkan untuk berkendara. Berikut gambar menu pasang seat belt

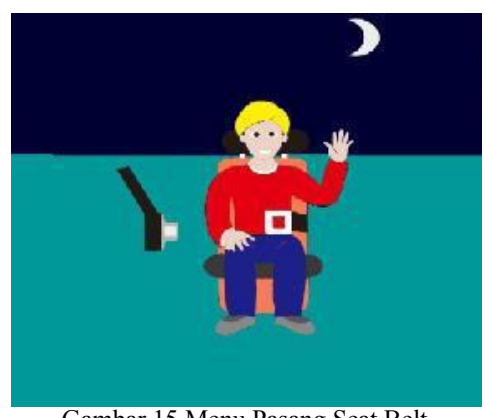

Gambar 15 Menu Pasang Seat Belt

Pada Gambar 15, pemain dapat mengeser seat belt yang ada di sebelahnya untuk dipasangkan ke pengendara, apabila dipasang secara benar maka pemain dapat melanjutkan ke tahap berkendara.

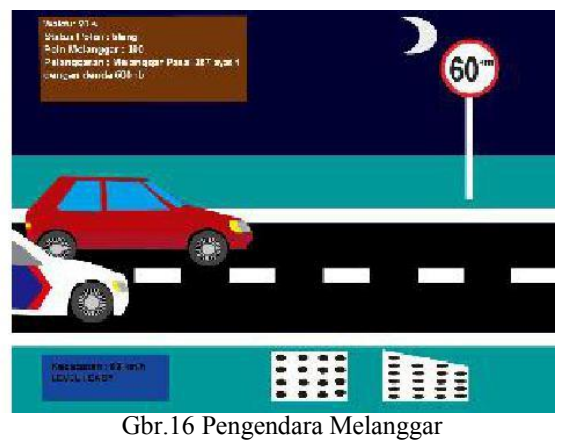

Pada Gambar 16, dijelaskan bahwa pengendara menerobos rambu lalu lintas, sehingga aplikasi memberikan catatan pelanggaran pasal yang dikenakan sesuai dengan undang-undang lalu lintas yang berlaku Tindakan penegak disiplin seperti Gambar 17
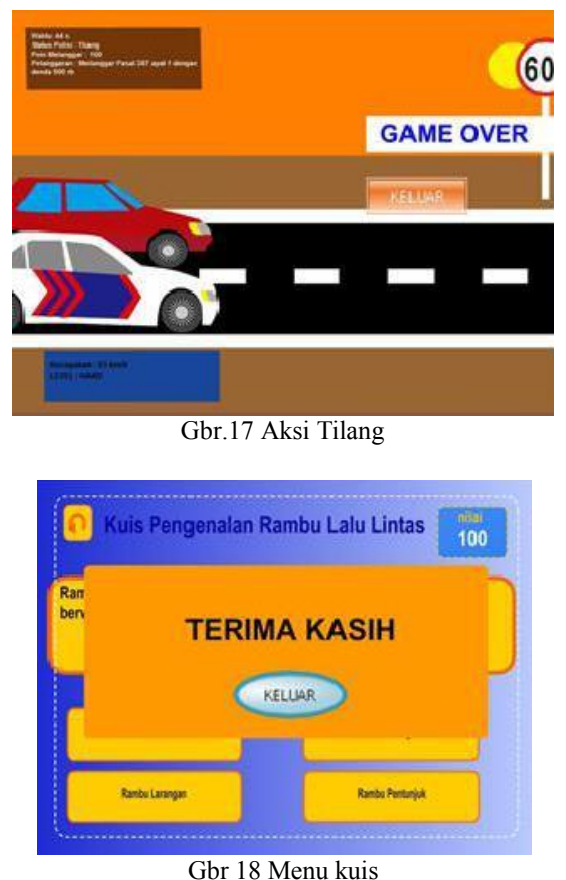

Pada Gambar 18, dijelaskan bahwa terdapat pertanyaan dan jawaban pilihan ganda. Pilihan ganda pada setiap pertanyaan disediakan sebanyak 4. Sedangkan untuk jumlah soal sebanyak 5 soal dengan bobot per-soal sebanyak 20 poin sehingga apabila benar semua maka skor nilai adalah 100.

\section{B. Pengujian pada Aplikasi Android}

Pada gambar 19 berikut ini adalah tampilan icon pada aplikasi pengenalan rambu lalu lintas dengan nama icon coba yang telah di pasang pada perangkat smartphone 

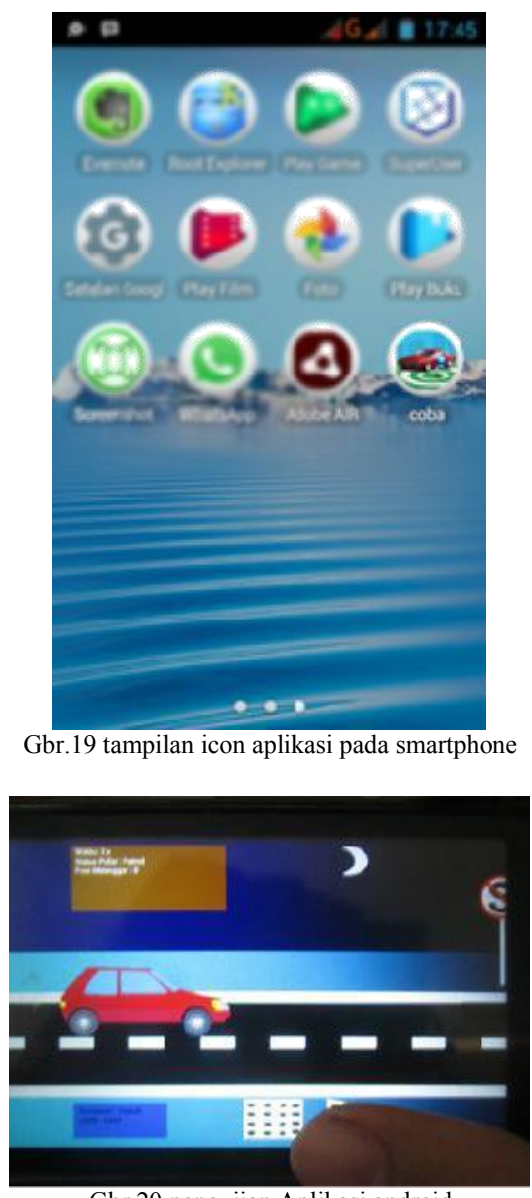

Gbr.20 pengujian Aplikasi android

Pada gambar 20, merupakan tampilan pengujian yang berhasil diterapkan pada aplikasi android dengan menggunakan perangkat smartphone, dimana user dapat mengendarai kendaraan dengan menekan tombol gas dan rem pada aplikasi yang dijalankan

\section{A. Kesimpulan}

\section{PENUTUP}

Dari penelitian yang telah dilakukan, maka diperoleh kesimpulan

1) Aplikasi dapat memberikan pemahaman tentang peraturan pasal rambu lalu lintas serta dapat memberikan pembelajaran terhadap masyarakat ramburambu yang ada di setiap perlintasan jalan

2) Metode fuzzy berhasil diterapkan pada aplikasi, pada bagian game terdapat proses/skenario yang dirancang menggunakan 2 aksi yaitu aksi patroli ketika tidak terjadi pelanggaran dan tilang jika pengendara melanggar rambu lalu lintas

\section{B. Saran}

Berikut saran-saran untuk penelitian pengembangan selanjutnya karena penelitian ini masih ada beberapa kekurangan, sehingga untuk penyempurnaan dapat ditambahkan :

1) Kombinasikan aplikasi dengan menggabungkan beberapa animasi

2) Desain aplikasi dapat ditambahkan beberapa ikon atau karakter

3) Aplikasi dapat dikembangkan dengan pilihan macam arena

4) Desain aplikasi dapat dikembangkan ke dalam bentuk 3D

Ucapan Terima Kasih

Ucapan terima kasih kami sampaikan kepada:

1. Bapak dan Ibu dosen pembimbing yang telah banyak memberikan ilmu kepada saya.

2. teman - teman yang selalu memberikan dukungan dan semangat dalam pengerjaan karya ini.

\section{REFERENSI}

[1] Akin \& Akbas. 2010. Faktor dan Kondisi Terjadinya Kecelakaan Lalu Lintas pada Pengendara Kendaraan

[2] Ichwan M dan Hakiky, Fivin. 2011. Pengukuran Kinerja Goodreads Application Programming Interface (API) Pada Aplikasi Mobille Adroid. Jurnal Informatika No.2, Vol. 2, Mei-Agustus 2011

[3] Kusumadewi, S., dan Purnomo, S. 2010. Aplikasi Logika Fuzzy untuk Pendukung Keputusan. Penerbit : Graha Ilmu. Yogyakarta.

[4] Latief, Nurul M. 2013. Training Monitoring System for Cyclist Based on Android Application Development. Department of Communication Engineering, Faculty of Electrical Engineering, Universiti Teknologi Malaysia

[5] Mashudi, I, Arif. 2012. Penerapan Perilaku Cerdas Pada Obyek di dalam Game Flash Tower Defense. Fakultas Teknologi Informasi, Institut Teknologi Sepuluh Nopember, Surabaya.

[6] Muhammad Awaluddin. 2016. Pendekatan Viktomologi dalam Kasus Kecelakaan Lalu Lintas yang menyebabkan hilangnya Nyawa Orang lain. Fakultas Hukum, Universitas Hasanuddin Makassar.

[7] Nadhillah, A. 2013. Persepsi Masyarakat Tentang Safety Riding Daytime Running Led. Fakultas Ilmu Sosial dan Politik : Universitas Pembangunan Nasional Surabaya.

[8] Nazruddin, Safaat H. 2012. Pemrograman Aplikasi Mobile Smartphone dan Tablet PC Berbasis Android. Informatika

[9] Pamungkas, S. 2012. Pentingnya Edukasi Safety Riding Sejak Dini. Tersedia di : http://autos.okezone.com/read/2012/02/07/53/571257/pentingnyaedukasi-safety-riding-sejak-dini. Tanggal akses 1 September 2016

[10] Reo Angga Ardenia dan Alexius Endy Budianto. 2015. Penerapan Metode Fuzzy untuk Game Keselamatan Pengendara Sepeda Motor Berbasis Android. Fakultas Teknik, Universitas Kanjuruhan, Malang

[11] Sugiman, V, R., Cahyana, R dan Bunyamin. 2014. pengenalan aplikasi rambu lalu lintas berbasis android menggunakan metode prototyping. ISSN : 2302-7339 Vol. 11No. 12014

[12] Torrente, J., Moreno-Ger, P., Martínez-Ortiz, I., dan FernandezManjon, B. 2009. Integration and Deployment of Educational Games in e-Learning Environments: The Learning Object Model Meets Educational Gaming. Educational Technology \& Society, 12 (4), 359371.

[13] Undang-Undang RI. 2004. Pedoman dan Penyediaan dan Pemanfaatan Prasaranan dan Sarana Jalan. Jakarta : Undang - Undang Republik Indonesia. 